\title{
Technical and economic viability of electric power plants on the basis of renewable energy resources regarding hierarchical structure
}

\author{
Mikhail Balzannikov ${ }^{1, *}$ \\ ${ }^{1}$ Samara State Technical University, 194 Molodogvardeyskaya St., 443001, Samara, Russia
}

\begin{abstract}
The article deals with power stations working on the basis of non-renewable energy resources and finite resources which will inevitably come to depletion in the future. These installations produce considerable negative impact on the environment, including air pollution. It is noted that considerable amounts of emissions of harmful substances accounts for the share of small thermal installations which aren't always considered in calculations of pollution. The author specifies that emission reduction of harmful substances should be achieved due to wider use of environmentally friendly renewable energy resources. It is recommended to use hierarchical structure with the priority of ecological and social conditions of the region for technical and economic viability of consumers' power supply systems and installations, based on renewable energy resources use. At the same time the author suggests considering federal, regional and object levels of viability. It is recommended to consider the main stages of lifecycle of an object for object level: designing, construction, operation, reconstruction of an object and its preservation. The author shows the example of calculation of power plant efficiency, based on renewable energy resources during its reconstruction, followed by power generation increase.
\end{abstract}

\section{Introduction}

The majority of the types of energy used by mankind, derives from the Sun including fossil energy carriers as they represent the solar energy, chemically accumulated. All power sources can be divided into exhaustible and inexhaustible, or on non-renewable and renewable $[1,2]$. Nowadays the main sources of power supply are fossil organic fuel sources. However, it is necessary to consider the following circumstances:

Non-renewable power sources produce finite resources and will inevitably come to exhaustion in the future. According to the research of the international commissions, at the existing level of scientific and technical progress the energy consumption based on organic fuel will have been able to meet the demands only partially by 2020 . Therefore, acute shortage of energy is possible, if we consider only organic power sources. It, in turn, can lead to growing animosity between the countries and to the conflicts.

\footnotetext{
*Corresponding author: balzannikov@,samgasu.ru
} 
2. The thermal power is the additional power source in relation to balance of the energy circulating on the earth. Hard work of power stations is capable to cause a thermal overheat of the environment, causing global negative ecological consequences.

3. The negative impact of the power stations using organic fuel on the environment increases. As experts and scientists note, more than 6 million of thermal and power complexes work as a part of fuel and energy economy of Russia. At the same time annually about 65 million tonnes of harmful substances are released into the atmosphere. $23 \%$ of them (16 million tonnes) accounts for the share of fuel and energy complex (FEC). These emissions are: 4.6 one million tonnes of ashes, 7.3 million tonnes of sulphurous anhydride and 2.7 million tonnes of nitrogen oxides. The example of work of the city power station is given in fig. 1. As we see, considerable pollution of the air is evident. Besides, it is necessary to take into account that about $15 \%$ of all emissions of harmful substances accounts for the share of the small thermal installations which aren't considered in the statistical report.

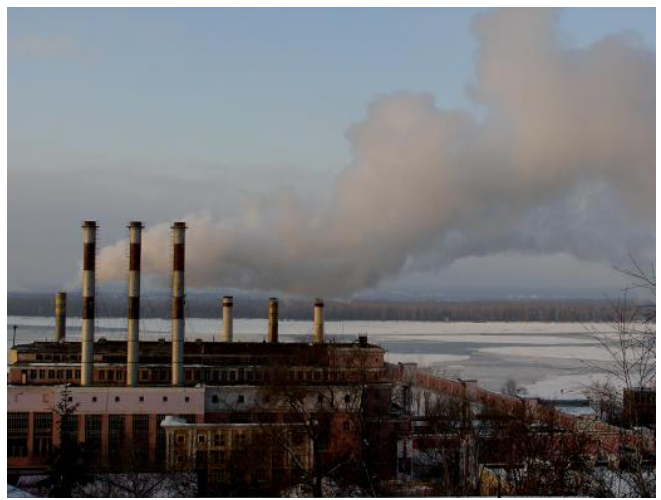

Fig. 1. Overall view on the municipal power station during its operation in winter. (author's photo)

Products of fuel combustion pollute the air with nitrogen oxides and are gray, ashes with toxic cancerogenic substances, heavy metals, etc. The admissible hygiene standards exceed 10-50 times, taking into account harmful substance content.

4. Nowadays power plant objects annually consume up to 30 billion $\mathrm{m}^{3}$ of water, the most part of which has passed through production cycle, comes to reservoirs and contains heavy metals, oil products, phenol and other toxic components which repeatedly exceed maximum permissible concentration.

It is obvious that reduction of atmospheric emissions of greenhouse gases and harmful substances should be gained, except other methods, due to wider use of environmentally friendly renewable energy sources.

\section{Materials and Methods}

Significant progress is observed in the last 20 years in the field of use of the renewable energy resources (RER). Transition of power systems to renewable energy resources (RES) from a Research and Development stage to the stage of industrial and commercial use is provided due to large financial investments in this industry, and also adoptions of legal acts and the political decisions made in certain countries and at the interstate level, So, in 1996 the World Solar Program (WSP), approved by the 53rd session of the United Nations General Assembly as a constituting resolution on sustainable development, was adopted. According to the report of the European Commission, the purpose of the EU in the field of RES is coordination of actions and expansion of large-scale use of the RES providing 
achievement of production of $12 \%$ of the electric power of RES. According to the global purposes of "The energy strategy of the USA" acknowledged as necessary "... to promote development of the technologies, allowing to increase return of renewable energy to 25000 MW and to maintain viability of the existing hydroelectric capacities". The federal government in Germany set the goal to raise a share of RES in total electric power production to $50 \%$ by 2050 [3].

Potential of renewable energy resources use is very high and many countries set very serious problems concerning its useful use. However, implementation of these tasks requires carrying out actions in legislative, administrative, organizational, technical, educational, information spheres. Experience of the countries with widely detailed programs of use of RES confirms such integrated approach.

The following most known specific general features are peculiar for renewable energy resources [4-6, 12-14]:

- low specific density of energy (per unit length, area, etc.);

- big territorial and temporary unevenness of its distribution;

- essential dependence on natural factors and interruptibility of power return;

- rather big material capacity, and consequently low economic indicators: essential capital investments and operating costs;

- considerable difficulties in concentration of energy and creation of large power plants;

- a possibility of their use in hardly accessible areas for power supply of local consumers;

- high prospects of application of automated control systems and work of installations without participation of a service personnel;

- specific impact on the surrounding environment.

These features have significant effect on an opportunity and on schemes of use of the considered energy types.

It should be noted that Russia had one of the leading positions in the development of renewable power and use of power stations on their basis in the past. In particular, in 1970 in the Crimea the first wind turbine by capacity of $100 \mathrm{~kW}$ in the world was built. Wind power units of small capacity were produced in big amounts in $40^{\text {th }}$ and $50^{\text {th }}$ years of the last century in our country.

Russia was the first to construct geothermal power plant, and also the first to carry out experiments on new methods of use of the geothermal carrier and low-temperature heat for energy consumption. Research of Russian scientists in the field of photoelectricity is acknowledged around the world, and the first solar photo-electric batteries for the space purposes were created also with participation of our specialists. Besides, Russia is the second country in the world which constructed tidal hydroelectric power station, having implemented a unique floating method of a construction which gained wide recognition of all hydro technicians of the world.

All types of energy derive from the Sun. It radiates a huge number of energy. Energy of $100 * 10^{15} \mathrm{~W}$, and for a year of $10^{18} \mathrm{kWh}$ reach the Earth, i.e. 10 thousand more energy consumed around the world. Even, if to consider that less than a half of radiation reach the Earth's surface, power stations can take energy which will exceed annual electricity consumption around the world more than 200 thousand times.

Use of solar energy occupies one of the leading positions among other types of RES now. The greatest preference is given to direct use of solar radiation, for example, due to use of solar-heat traps or collectors (fig. 2). 


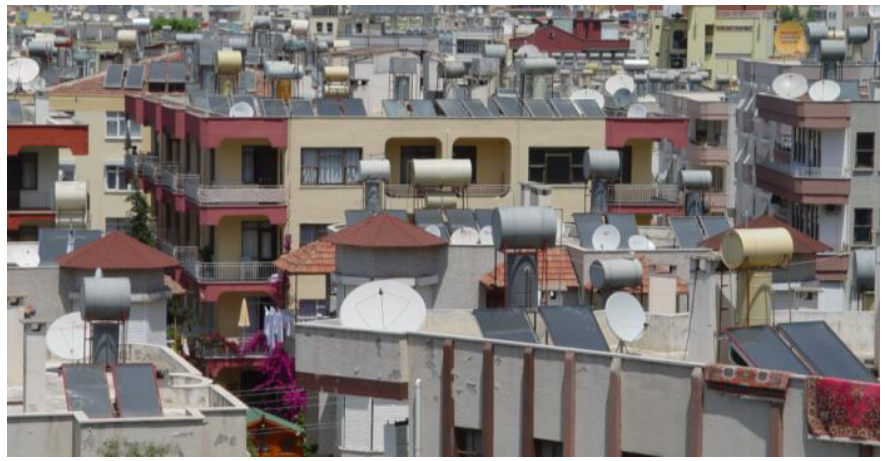

Fig. 2. Use of solar-heat traps, located on the roofs of the houses (author's photo)

Important features of power stations use on the basis of renewable types of energy is the right choice of viability technique and efficiency criteria of their use, and also determination of their key parameters. The central area of Russia and, in particular, the Samara region doesn't belong to first-priority areas of mastering renewable energy sources. In particular, the potential of solar and wind energy is estimated as average here. So, annual average wind speed is only $4-5 \mathrm{~m} / \mathrm{s}$. However, general wind energy levels are considerable. Therefore, research in increase of wind installations efficiency in zones with an average wind potential and ensuring their economic appeal is reasonable.

It should be noted that for the purpose of enhancement of methods of technical and economic viability of systems of consumers' power supply from the installations working on the RES use of a hierarchical structure is offered. At the same time the most important priority component of a technique is the analysis of ecological and social priorities of power stations on the basis of RES, and also importance of development of this direction of power is designated.

The hierarchical structure of viability for development of power stations on the basis of RES, that consider ecological conditions includes [7, 8]:

1. Federal level. At this level the development program of productive forces in the region is determined. At the same time feasibility and cost efficiency of their level increase in the considered region with simultaneous power supply growth. Production sphere reduction without increase in power/weight ratio of production industries with the subsequent reorientation of fields of activity of the population can be an alternative. The general demand of the region in energy, taking into account ecological situation, is optimized; the choice between energy and other directions of development of the region is made.

2. Regional level. The analysis of the choice of various types and a quantitative ratio of the power stations using different types of power sources and exerting various negative impact on the environment is made. Power stations that use RES directly compete with other types of power plants. It is important to emphasize the need of consideration of ecological restrictions at this level and creation of regional (external in relation to objects) conditions and factors that stimulate introduction of ecologically safe power stations and actions which improve the environment.

3. Object level. This level is optimization calculations for a specific object of the chosen type of the power station taking into account its impact on the environment. In turn, it is reasonable to perform the analysis at the following sublevels (stages):

3.1. A project stage that develops:

- optimization of key parameters of an energy object taking into account its impact on the environment; 
- choice of nature protection actions and their technical and economic viability during the designing process;

- choice of the location of the main constructions producing minor negative anthropogenic effects.

3.2. Construction stage. It includes:

- choice and reasons for organizational processes of a construction;

- reasons for engineering procedures of the construction works providing work performance improvement, elimination of polluting waste water discharge, rehabilitation of the territory and other requirements.

3.3. Operational stage. Important components of this stage are:

- prevention of pollution and emissions of harmful substances;

- choice of ecologically reasonable modes of operation;

- accident prevention [9].

3.4. Stage of object reconstruction. Among the main objectives of a stage:

- increase in production of energy volume;

- cost value decrease of energy production;

- elimination or reduction of the definite negative impacts of an object on the environment as a result of technological progress and use of its achievements.

3.5. Stage of liquidation or preservation of an object, which is characterized by:

- ensuring effective recycling of material resources;

- minimizing negative impact on the environment of production consequences.

\section{Results}

Use of a hierarchical structure in the Middle Volga region of Russia with its high industrial potential and considerable extent of environmental pollution is especially important. According to provided technique calculation of technical and economic viability of production volume increase of the electric power in case of reconstruction of an energy object that corresponds to level 3 - object level, to a stage 3.4 - object reconstruction.

Calculations are made on the basis of integrated effect method [3,10,11]. Results of calculations are presented in the graphic form in fig. 3. Here dependences of the minimum charges of energy consumption $-\mathrm{C}$, cents, efficiency of power of installation $-K_{N}, \%$, for different values of a discount rate $(0,4$ and 8$) \%$ are given at the specific cost of capital investments into one kilowatt of extra power $\mathrm{k}=1000$ dollars. These results demonstrate under what conditions and what minimum charge on energy consumption will prove reconstruction of an energy object on the basis of renewable energy resources to be economically reasonable.

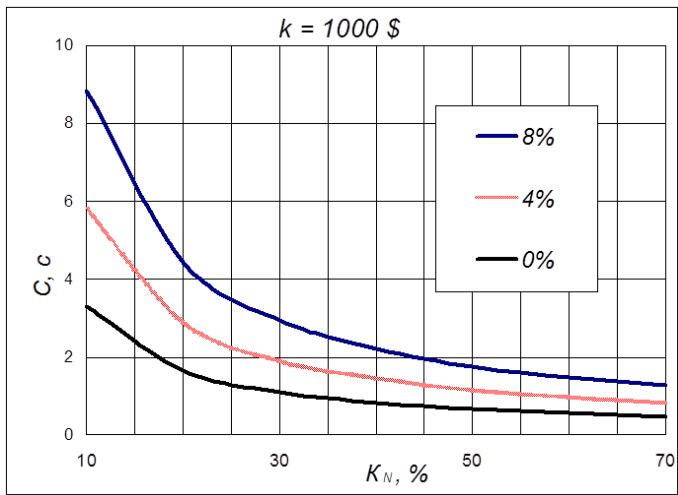

Fig. 3. Dependency graph of minimum charge on energy consumption 


\section{Discussion}

We believe that this method has considerable advantages, as it takes into account technoeconomic and environmental conditions in the area of a certain energy-specific object when analyzing the relevance of reconstruction to increase electric power generation. Economic: influence of unit cost of capital investments to one kilowatt of additional capacity, as well as discount rates. Technical: influence of power plant capacity utilization. This parameter characterizes the regularity of plant loading over a certain of time (usually days). The smallest value of this coefficient corresponds to power plants operating in the peak area of a daily load curve. The largest value is for stations in the primary zone. Environmental conditions of the area could be taken into account in two ways: the first is due to the participation rate in co-funding of reconstruction from commercial organizations or municipal authorities interested in the project; the second is through the provision of subsidized tariff for additional electricity supply.

Charts show which minimum tariff for electricity will ensure cost-effectiveness of reconstruction. But this is not all. They can be used to solve an inverse problem: if electricity consumer is willing to pay a certain amount per $1 \mathrm{kWh}$ of additional electricity, these charts will help determine which specific investments can be spent by the investor for such an renovation for different operation modes of the station itself: peak, half-peak or basic.

The value of the suggested method lies in its clarity, orientation on pricing policies in this area in relation to a crucial product of today - electricity, in mobility of its analysis, in the fact that it considers environmental situation in the area as well as in the ability to repeat the analysis in case of changes in economic conditions in the area (for example, a change in the discount rate).

Such an approach can be successfully used on other levels of the hierarchical structure described above.

Thus, the developed hierarchical approach makes it possible to design an effective and coherent strategy for energy development in the region with account of the ecological environment and its state in regard to the rise in energy consumption as in the region as a whole, and in the area of an energy-specific object.

In further research we recommend paying attention to the development of an automated system and software, which allows to perform a technical and economic analysis of the efficiency of power stations, using renewable energy, at all levels of the described hierarchical structure and which takes into account changes of environmental conditions on the territories in question.

\section{Conclusions}

The main conclusions of the research can be formulated as follows:

1. The power stations working on the basis of non-renewable energy resources use final resources which in the future will inevitably come to depletion. These installations produce considerable negative impact on the environment. Emission reduction of harmful substances should be achieved due to wider use of environmentally friendly renewable energy resources.

2. Hierarchical structure with consideration of ecological and social conditions of the region is recommended for technical and economic viability of consumer's power supply from the installations, working on the renewable energy resources. Federal, regional and object levels are appropriate for consideration in hierarchical structure. 


\section{References}

1. V.V. Elistratov, Renewable energy (Saint Petersburg politechnical university publishing house, 2011)

2. M.I. Balzannikov, S.V. Evdokimov, Yu.M. Galitskova, Industrial and civil engineering 3, 16-19 (2014)

3. M.I. Balzannikov, V.V. Elistratov, Renewable energy resources. Aspects of complex use (OFORT, Samara, 2008)

4. F. Svitala, Yu.M. Galitskova, S.V. Evdokimov, Industrial and civil engineering 12, 8790 (2014)

5. S.V. Evdokimov, Urban Construction and Architecture 2, 68-72 (2012) doi: 10.17673/Vestnik.2012.02.13

6. S.V. Evdokimov, Industrial and civil engineering 8, 35-38 (2010)

7. M.I. Balzannikov, Proceedings of Voizhskiy Regional Division of Russian Akademy of Architecture and Construction Sciences 8, 173-185 (2005)

8. M.I. Balzannikov, Academician Yu.S. Vasiliev's school of Science in the field of energy and environmental protection: Proceedings of the SPb, 25-39 (2004)

9. Evdokimov S.V., Dormidontova T.V. Urban Construction and Architecture 1, 64-68 (2012) doi: 10.17673/Vestnik.2012.01.12

10. M.I. Balzannikov, V.A. Seliverstov, Industrial and Civil Engineering 8, 17-19 (2010)

11. M.I. Balzannikov, Urban Construction and Architecture 4, 86-92 (2015) doi: 10.17673/Vestnik.2015.04.11

12. G. Radovic, V. Murgul, N. Vatin, Applied Mechanics and Materials, 641-642, 634638 (2014)

13. P. Polina, N. Vatin, V. Murgul, Applied Mechanics and Materials, 680, 510-516 (2014)

14. E. Aronova, N. Vatin, V. Murgul, Procedia Engineering, 117, 771-779 (2015) 